\title{
Whole Body Bone Tissue and Cardiovascular Risk in Rheumatoid Arthritis
}

\author{
Claudiu Popescu,, ${ }^{1,2}$ Violeta Bojincă, ${ }^{1,2}$ Daniela Opriş, ${ }^{1,2}$ and Ruxandra Ionescu ${ }^{1,2}$ \\ 1 "Sfânta Maria" Clinical Hospital, 37-39 Ion Mihalache Boulevard, District 1, 011192 Bucharest, Romania \\ ${ }^{2}$ Department of Internal Medicine and Rheumatology, "Carol Davila" University of Medicine and Pharmacy, \\ 011192 Bucharest, Romania \\ Correspondence should be addressed to Claudiu Popescu; dr.reumatologie@gmail.com
}

Received 19 February 2014; Revised 23 March 2014; Accepted 23 March 2014; Published 8 April 2014

Academic Editor: Jun Iwamoto

Copyright (C) 2014 Claudiu Popescu et al. This is an open access article distributed under the Creative Commons Attribution License, which permits unrestricted use, distribution, and reproduction in any medium, provided the original work is properly cited.

\begin{abstract}
Introduction. Atherosclerosis and osteoporosis share an age-independent bidirectional correlation. Rheumatoid arthritis (RA) represents a risk factor for both conditions. Objectives. The study aims to evaluate the connection between the estimated cardiovascular risk (CVR) and the loss of bone tissue in RA patients. Methods. The study has a prospective cross-sectional design and it includes female in-patients with RA or without autoimmune diseases; bone tissue was measured using whole body dual X-ray absorptiometry (wbDXA); CVR was estimated using SCORE charts and PROCAM applications. Results. There were 75 RA women and 66 normal women of similar age. The wbDXA bone indices correlate significantly, negatively, and age-independently with the estimated CVR. The whole body bone percent (wbBP) was a significant predictor of estimated CVR, explaining 26\% of SCORE variation along with low density lipoprotein $(P<0.001)$ and $49.7 \%$ of PROCAM variation along with glycemia and menopause duration $(P<0.001)$. Although obese patients had less bone relative to body composition (wbBP), in terms of quantity their bone content was significantly higher than that of nonobese patients. Conclusions. Female patients with RA and female patients with cardiovascular morbidity have a lower whole body bone percent. Obese female individuals have higher whole body bone mass than nonobese patients.
\end{abstract}

\section{Introduction}

Atherosclerosis and osteoporosis share an age-independent bidirectional correlation $[1,2]$, although they were considered to be independent pathologies. On one hand, low bone mass is associated with subclinical [3] and clinical atherosclerosis, manifested as cardiovascular morbidity $[4,5]$ and mortality [6]. On the other hand, cardiovascular disease is associated with low bone mass and with a higher risk of fragility fractures [7]. There is no unifying theory which can explain a deterministic link between atherosclerosis and osteoporosis, if any. Certainly, bone modeling and vascular calcification have common biological processes and risk factors (e.g., smoking, inactivity, and inflammation) [8]. We can cite RA among these factors, as a crossroad of atherosclerosis and osteoporosis. The main cause of mortality in RA is the cardiovascular pathology $[9,10]$. Adding to the classical cardiovascular risk (CVR) factor, chronic inflammation $[11,12]$ and disease duration [12] contribute decisively to the excess cardiovascular mortality in RA. The background of this observation is the inflammatory pathogenesis of RA which is associated with accelerated atherosclerosis [13], both clinically and subclinically $[14,15]$. Therefore, EULAR recommends annual CVR evaluation in RA patients [16], knowing the fact that RA is an independent CVR factor [9], similar in importance with diabetes mellitus (DM) [17]. One of the main consequences of RA is osteoporosis. It appears early in the disease course, two times more prevalent than in the general population $[18,19]$. Adding to the risk factor of primary osteoporosis, the bone loss in RA is associated with the presence of autoantibodies [18], glucocorticoid therapy, disease activity (the activation of osteoclasts by mean of 
the RANK pathway) [20, 21], and disability. Because of the high risk of fractures in RA $[22,23]$, RA patients should routinely undergo dual X-ray absorptiometry (DXA) in order to diagnose and monitor osteoporosis. The advantage is that at the same time with DXA measurements one can evaluate the patient's body composition. DXA has been validated as a precise method for estimating body composition [24]. If coupled with CVR estimation, the DXA technique could become the common denominator for the complex management of atherosclerosis and osteoporosis in RA. In this context, the study aims to evaluate the correlation between the estimated CVR and whole body bone loss, emphasizing $\mathrm{RA}$ as a common risk factor for both conditions.

\section{Methods and Materials}

2.1. Patients. The study was cross-sectionally designed to include female in-patients, admitted to the hospital in the random order of presentation for clinical and biological reevaluation. The subjects were classified as either RA patients, according to the 2010 ACR/EULAR criteria [25], either as having no chronic inflammatory autoimmune disease. Each patient gave written informed consent and the study was approved by the local ethics committee.

2.2. Measurements. Demographic data and smoking status were recorded by means of anamnesis. The bone tissue was evaluated by a single certified clinical densitometrist (CP) using whole body DXA (wbDXA; Lexxos C05LX223), which records variables such as bone tissue density/mass (BTD/M), $T$ - and $Z$-scores $\left(T / Z_{\mathrm{wb}}\right)$, and bone tissue percent (BTP; Figure 1). The classic anthropometric indices, such as height, weight, abdominal circumference (AC), and hip circumference $(\mathrm{HC})$, were measured using a mechanical scale $(0.1 \mathrm{~kg}$ maximal error), a wall stadiometer $(0.3 \mathrm{~cm}$ maximal error), and a centimeter graded tape. Using these measurements, we computed the derived anthropometric indices: body mass index (BMI; weight divided by square height), waist-to-hip ratio (WHR; AC divided by $\mathrm{HC}$ ), conicity index (CI; AC divided by the square root of weight to height ratio multiplied by 0.109 ). Erythrocyte sedimentation rate (ESR) was measured by the Westergren method (normal range according to age). The concentration of C-reactive protein (CRP) was measured by immunonephelometry (normal range $<5 \mathrm{mg} / \mathrm{L}$ ). Arterial hypertension (AHT) was defined after two measurements (auscultatory sphygmomanometer; $5 \mathrm{mmHg}$ error) if systolic pressure $\geq 140 \mathrm{mmHg}$, or diastolic pressure $\geq 90 \mathrm{mmHg}$, or if the patient was on blood pressure lowering therapy [26]. Ischemic heart disease (IHD) was defined on electrocardiographic criteria or on a history of acute coronary syndromes, stable angina, conduction and rhythm disturbances, and ischemic heart failure [27]. The recorded antiplatelet agents were aspirin and clopidogrel. Dyslipidemia was defined as triglycerides $>150 \mathrm{mg} / \mathrm{dL}$, total cholesterol $>200 \mathrm{mg} / \mathrm{dL}$, low-density lipoproteins (LDL) > $100 \mathrm{mg} / \mathrm{dL}$, high-density lipoproteins (HDL) $<50 \mathrm{mg} / \mathrm{dL}$, or treatment with statins and fibrates [28]. Diabetes mellitus was defined as two fasting plasma glucose levels $>126 \mathrm{mg} / \mathrm{dL}$
(FPG), one FPG $>200 \mathrm{mg} / \mathrm{dL}$, or treatment with insulin/oral antidiabetic agents [29]. Obesity was defined as a BMI $\geq$ $30 \mathrm{~kg} / \mathrm{m}^{2}$. The metabolic syndrome was defined using the 2006 International Diabetes Federation criteria [30]. The CVR was estimated using high risk SCORE charts, appropriate for the Romanian population [31], and quick check and health check PROCAM applications [32], according to EULAR recommendations [16].

2.3. Statistics. The normal distribution of data was assessed using descriptive statistics, normality and stem-and-leaf plots, and the Lilliefors corrected Kolmogorov-Smirnov test. Normally distributed data were reported as means with standard deviations and their correlations and differences were assessed with Pearson coefficients and $t$-tests, respectively. Non normally distributed data were reported as medians with intervals and their correlations and differences were assessed with Spearman coefficients and Mann Whitney tests, respectively. Qualitative data were expressed as absolute and percent frequency and their differences were assessed using $\chi^{2}$ tests (or Fisher tests where appropriate). The influence of whole body bone tissue on CVR was studied using multiple linear regression and covariance analysis (ANCOVA). All tests were considered significant if $P<0.05$ and were done using SPSS v.17 for Windows (SPSS Inc., Chicago, USA, 2008).

\section{Results}

3.1. RA-Normal Subjects Comparison. Table 1 summarizes the variables recorded in the two groups. Although RA patients do not have longer menopause duration or higher menopause frequency, most of their wbDXA indices are significantly lower than those of normal patients. It should be noted that RA patients had a mean disease duration of $12.8 \pm 10$ years, 66 patients $(86.8 \%)$ were RF positive and 44 patients (57.9\%) were anti-CCP positive. RA was moderately active in the studied group (mean DAS28 of $4.25 \pm 1.21$; mean SDAI of $63.3 \pm 40.9)$. As to treatment regimes, 68 patients $(89.5 \%)$ were receiving methotrexate, 35 patients (46\%) were receiving oral glucocorticoids, and 25 patients (32.9\%) were receiving bisphosphonates.

3.2. Bone Tissue and Cardiovascular Risk. As pointed out in Table 2, the wbDXA indices of bone tissue are significantly and negatively correlated with the CVR estimation by all three instruments. The covariance analysis revealed that this correlation is independent of age, menopause, IHD, smoking, BMI, obesity, AHT, dyslipidemia, DM, inflammation, and metabolic syndrome.

The multiple linear regression of BTP with CVR scores revealed notable results. Except for BTP, SCORE correlated significantly with age, menopause duration, height, AC, HC, WHR, BMI, CI, LDL, and total cholesterol. Of these, we excluded age, since it is part of SCORE protocol, and WHR, BMI, and CI, since they where derived from variables that were already correlated with SCORE. The remaining variables significantly explained $47 \%$ of SCORE 


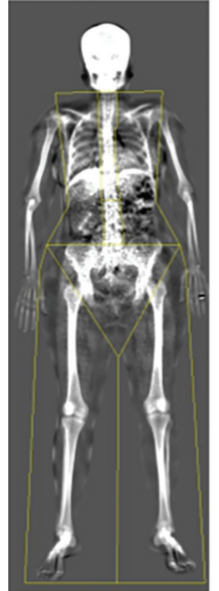

Bone

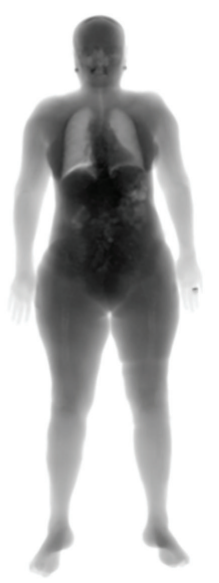

Tissue

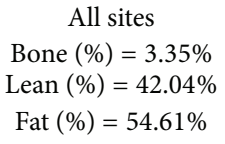

Selected sites

Bone $(\%)=2.82 \%$

Lean $(\%)=39.58 \%$

Fat $(\%)=57.61 \%$

FIGURE 1: Body mass composition result, indicating the bone tissue percent with regard to body mass (Lexxos C05LX223 software v6.0551).

variation $\left(R^{2}=0.472 ; P<0.001\right.$; standard method), but the contribution of height, $\mathrm{AC}, \mathrm{HC}$, and total cholesterol were not significant, being thus eliminated from the regression model. The two remaining predictors were introduced in the equation in the order LDL-BTP and significantly explained $26 \%$ of SCORE variation $\left(R^{2}=0.262 ; P<0.001\right.$; hierarchical method). In this two-parameter model, LDL independently explained $3.4 \%$ of SCORE variation, while BTP explained $25 \%$.

Except for BTP, PROCAMqc correlated significantly with age, menopause duration, height, body mass, AC, HC, WHR, BMI, CI, and glycemia. Of these, we excluded height, body mass, WHR, BMI, and CI on the same grounds. The standard multiple linear regression of the remaining variables with PROCAMqc generated a significant equation which predicted $51.3 \%$ of its variation $\left(R^{2}=0.513 ; P<0.001\right)$. The contribution of AC and HC was not significant though. The three remaining predictors (menopause duration, glycemia, and BTP) were introduced in the equation in that order and significantly explained $50 \%$ of PROCAMqc variation $\left(R^{2}=\right.$ 0.497; $P<0.001$; stepwise method). In this three-parameter model, menopause duration independently explained $23.3 \%$ of PROCAMqc variation; glycemia explained $16.6 \%$, while BTP explained $10 \%$.

3.3. Bone Tissue and CVR Factors. As was expected from bone measurements, the wbDXA indices correlated significantly and negatively with age and were significantly higher in the premenopause period (Table 3). Moreover, these indices correlated significantly with the classical anthropometric measurements, in an age-independent manner (Table 4). The wbDXA bone indices varied significantly according to the presence or the absence of classic CVR factors (Table 5). For example, obese patients had lower BTP than nonobese patients, but their bone quantity was significantly higher. It is interesting that patients with high fasting glycemia, when compared with normal glycemic patients, behaved in the same manner as obese patients with regard to wbDXA bone indices. In general, patients with inflammatory and cardiovascular pathology had a lower BTP.

\section{Discussion}

In clinical practice, bone density regions of interest in adults include the lumbar spine, the femoral neck, and the distal radius, since these measurements have a higher predicting value in the recognition of osteoporosis than the whole body measurements. Since the purpose our study was not to diagnose osteoporosis, but instead to evaluate the link between bone loss and cardiovascular risk, a whole body approach was deemed more appropriate in this fundamental science query.

The correlation between cardiovascular pathology and bone tissue has been observed in the general population, but RA is an appropriate condition in which the two entities can be studied. As to bone tissue, the previous studies noted that RA patients, compared to normal individuals, have a lower DXA bone density in the regions used for the diagnosis of osteoporosis (lumbar spine, hip, and distal radius) [33]. Our study proves that the entire skeleton of RA patients exhibits lower bone density and lower bone mass than normal individuals. It seems that inflammation, glucocorticoid treatment, and low BMI are accounting for this difference, since the two groups did not differ significantly in terms of the other osteoporosis risk factor included in the study (age, menopause prevalence and duration, and smokingsee Table 1). As to atherosclerosis, RA patients had a higher CVR than normal individuals, in spite of the fact that the control group did not have a favorable cardiovascular profile: the controls were non-RA but were admitted to the hospital for different internal medicine diagnoses. This is why the two groups had similar prevalence of metabolic syndrome, AHT, IHD, and DM and had a higher prevalence of obesity.

Without suggesting any deterministic direction, our study reports a correlation between wbDXA bone indices with the CVR estimated on three different scales (Table 2). 
TABLE 1: Comparison between RA and normal patients.

\begin{tabular}{|c|c|c|c|c|}
\hline & Variable & Normal $(n=66)$ & RA $(n=75)$ & $P$ \\
\hline & Age (years) & $56.7(9.7)$ & $56(11.4)$ & ns \\
\hline & Menopause & $53(80.3 \%)$ & $57(76 \%)$ & ns \\
\hline & MPD (years) & $13.1(9)$ & $14.3(7.9)$ & ns \\
\hline \multirow{7}{*}{ Bone tissue } & wbBTD $\left(\mathrm{g} / \mathrm{cm}^{2}\right)$ & $0.797(0.093)$ & $0.763(0.091)$ & 0.032 \\
\hline & wbBTM (kg) & $1.56(0.16-2.14)$ & $1.50(0.82-2.03)$ & $0.028^{*}$ \\
\hline & $Z_{\mathrm{wb}}(\mathrm{sd})$ & $-0.75(-2.5-1.5)$ & $-0.91(-3.8-0.9)$ & $0.015^{*}$ \\
\hline & $T_{\mathrm{wb}}(\mathrm{sd})$ & $-1.1(1)$ & $-1.5(1)$ & 0.035 \\
\hline & BTP (\%) & $2.76(0.38)$ & $2.73(0.37)$ & ns \\
\hline & $\operatorname{BTD}_{\text {lumbar }}\left(\mathrm{g} / \mathrm{cm}^{2}\right)$ & $0.887(0.159)$ & $0.857(0.212)$ & ns \\
\hline & $T_{\text {lumbar }}(\mathrm{sd})$ & $-0.5(-3.7-2.8)$ & $-0.7(-4.4-2.5)$ & $\mathrm{ns}^{*}$ \\
\hline \multirow{7}{*}{ Anthropometrics } & Height $(\mathrm{cm})$ & $159(5.7)$ & $160(6.2)$ & ns \\
\hline & Body mass (kg) & $74.5(13.4)$ & $69.8(14)$ & 0.044 \\
\hline & $\mathrm{WC}(\mathrm{cm})$ & $95.3(13.6)$ & $94.3(12)$ & ns \\
\hline & $\mathrm{HC}(\mathrm{cm})$ & $107.9(11.1)$ & $107.1(11)$ & ns \\
\hline & WHR & $0.88(0.06)$ & $0.88(0.05)$ & ns \\
\hline & $\operatorname{BMI}\left(\mathrm{kg} / \mathrm{m}^{2}\right)$ & $29.5(4.9)$ & $27.3(4.9)$ & 0.007 \\
\hline & $\mathrm{CI}$ & $0.60(0.14)$ & $0.57(0.12)$ & ns \\
\hline \multirow{7}{*}{ Laboratory } & LDL (mg/dL) & $126.5(38.3)$ & $131.5(30.2)$ & ns \\
\hline & HDL (mg/dL) & $58.5(19.8)$ & $52.2(11.3)$ & 0.021 \\
\hline & $\mathrm{TC}(\mathrm{mg} / \mathrm{dL})$ & $213.7(48)$ & $208.4(41.1)$ & ns \\
\hline & $\mathrm{TG}(\mathrm{mg} / \mathrm{dL})$ & $110.5(43-843)$ & $107.5(43-258)$ & $\mathrm{ns}^{*}$ \\
\hline & $\mathrm{FPG}(\mathrm{mg} / \mathrm{dL})$ & $103.5(80-210)$ & $96(74-243)$ & $0.001^{*}$ \\
\hline & $\operatorname{ESR}(\mathrm{mm} / \mathrm{h})$ & $20(3-126)$ & $28(4-103)$ & $0.008^{*}$ \\
\hline & CRP (mg/L) & $3.5(0.2-155)$ & $6.6(0.4-183)$ & $0.024^{*}$ \\
\hline \multirow{12}{*}{ Cardiovascular risk } & AHT & $42(63.6 \%)$ & $37(49.3 \%)$ & ns \\
\hline & Anti-AHT treatment & $38(57.6 \%)$ & $43(57.3 \%)$ & ns \\
\hline & IHD & $20(30.3 \%)$ & $29(38.7 \%)$ & ns \\
\hline & Antiplatelet & $17(25.8 \%)$ & $25(33.3 \%)$ & ns \\
\hline & Dyslipidemia & $49(74.2 \%)$ & $67(89.3 \%)$ & 0.019 \\
\hline & Statins/fibrates & $15(22.7 \%)$ & $26(34.7 \%)$ & ns \\
\hline & $\mathrm{DM}$ & $10(15.2 \%)$ & $3(4 \%)$ & 0.022 \\
\hline & MetS & $41(62.1 \%)$ & $45(60 \%)$ & ns \\
\hline & Obesity & $31(47 \%)$ & $18(24 \%)$ & 0.004 \\
\hline & Inflammation & $24(36.4 \%)$ & $49(65.3 \%)$ & 0.001 \\
\hline & Smoking & $16(24.2 \%)$ & $7(9.3 \%)$ & 0.017 \\
\hline & PROCAMqc (\%) & $2.1(1.4)$ & $2.7(1.9)$ & 0.033 \\
\hline
\end{tabular}

${ }^{*}$ Mann-Whitney test; RA: rheumatoid arthritis; MPD: menopause duration; BT M/D/P: bone tissue mass/density/percent; WC: waist circumference; HC: hip circumference; WHR: waist to hip ratio; BMI: body mass index; CI: conicity index; L/H DL: low/high density lipoproteins; TC: total cholesterol; TG: triglycerides; FPG: fasting plasma glucose; ESR: erythrocyte sedimentation rate; CRP: C-reactive protein; AHT: arterial hypertension; IHD: ischemic heart disease; DM: diabetes mellitus; MetS: metabolic syndrome; wb: whole body; qc: quick check; ns: not significant; sd: standard deviation.

This correlation is real within the study's limitations, since it does not depend on the effect of the established CVR factors (age, menopause, smoking, obesity, AHT, dyslipidemia, inflammation, DM, and metabolic syndrome). We must emphasize that all types of wbDXA bone measurement showed independent correlations with CVR, both those that estimate absolute bone mass ( $\mathrm{g}$ ) and those that measure aria density $\left(\mathrm{g} / \mathrm{cm}^{2}\right)$ and body mass fraction (\%). Secondly, these correlations are negative, meaning that CVR increases as bone mass, density, and percent decreases. Of all the wbDXA bone indices, BTP had the strongest correlations with CVR.
For this reason it was used in regression models, proving to be an independent and significant predictor of CVR estimation, alongside LDL, glycemia, and menopause duration.

The correlation of wbDXA bone indices with CVR exceeds the scope of the clinical instruments used to estimate it (SCORE, PROCAM), which do not incorporate important variables such as the presence or the absence of the metabolic syndrome. Our data showed that individuals with cardiovascular morbidity are different (see Table 5). Three comments are pertinent at this stage. The first refers to the controversial relationship between osteoporosis and obesity. One can argue 
TABLE 2: Correlation between wbDXA bone indices and estimated CVR.

\begin{tabular}{|c|c|c|c|c|c|c|}
\hline & \multicolumn{2}{|c|}{$\mathrm{RA}(n=75)$} & \multicolumn{2}{|c|}{ Normal $(n=66)$} & \multicolumn{2}{|c|}{ All $(n=141)^{8}$} \\
\hline & $r$ & $P$ & $r$ & $P$ & $r$ & $P$ \\
\hline \multicolumn{7}{|l|}{ PROCAMqc } \\
\hline wbBTD & -0.262 & 0.024 & -0.275 & 0.026 & -0.415 & $<0.001^{\S}$ \\
\hline$T_{\mathrm{wb}}$ & -0.256 & 0.028 & -0.278 & 0.024 & -0.419 & $<0.001^{\S}$ \\
\hline BTP & -0.645 & $<0.001^{\S}$ & -0.634 & $<0.001^{\S}$ & -0.549 & $<0.001^{\S}$ \\
\hline BTD $_{\text {lumbar }}$ & ns & ns & 0.243 & 0.049 & ns & ns \\
\hline$T_{\text {lumbar }}$ & ns & ns & 0.243 & 0.049 & ns & ns \\
\hline \multicolumn{7}{|l|}{ PROCAMhc } \\
\hline wbBTD & -0.311 & $<0.001^{\S}$ & -0.261 & 0.034 & -0.311 & $<0.001^{\S}$ \\
\hline$T_{\mathrm{wb}}$ & -0.307 & $<0.001^{\S}$ & -0.261 & 0.034 & -0.307 & $<0.001^{\S}$ \\
\hline BTP & -0.615 & $<0.001^{\S}$ & -0.592 & $<0.001^{\S}$ & -0.615 & $<0.001^{\S}$ \\
\hline $\mathrm{BTD}_{\text {lumbar }}$ & -0.323 & $0.006^{\S}$ & ns & ns & -0.282 & 0.001 \\
\hline$T_{\text {lumbar }}$ & -0.322 & $0.006^{\S}$ & ns & ns & -0.283 & 0.001 \\
\hline \multicolumn{7}{|l|}{ SCORE* } \\
\hline wbBTD & -0.413 & $<0.001^{\S}$ & -0.430 & $<0.001^{\S}$ & -0.437 & $<0.001^{\S}$ \\
\hline wbBTM & -0.269 & 0.001 & ns & ns & -0.285 & $0.001^{\S}$ \\
\hline$T_{\mathrm{wb}}$ & -0.417 & $<0.001$ & -0.437 & $<0.001$ & -0.441 & $<0.001^{\S}$ \\
\hline BTP & -0.550 & $<0.001^{\S}$ & -0.525 & $<0.001^{\S}$ & -0.525 & $<0.001^{\S}$ \\
\hline
\end{tabular}

${ }^{*}$ Spearman coefficients, the rest being Pearson coefficients.

${ }^{\$}$ correlations that remain significant after controlling for age.

\& correlations made by controlling for RA diagnosis.

CVR: cardiovascular risk; ns: not significant; wb: whole body.

TABLE 3: Whole body bone tissue according to age and menopause $(n=141)$.

\begin{tabular}{lccccccc}
\hline & \multicolumn{2}{c}{ Age } & \multicolumn{2}{c}{ MPD } & Before menopause & After menopause \\
& $r$ & $P$ & $r$ & $P$ & $(n=31)$ & $(n=110)$ \\
\hline wbBTD $\left(\mathrm{g} / \mathrm{cm}^{2}\right)$ & -0.349 & $<0.001$ & -0.374 & $<0.001$ & $0.828(0.065)$ & $0.765(0.095)$ & $<0.001$ \\
wbBTM $(\mathrm{kg})$ & -0.204 & 0.016 & -0.320 & 0.001 & $1.59(0.26)$ & $\mathrm{ns}$ \\
$T_{\text {wb }}(\mathrm{sd})$ & -0.351 & $<0.001$ & -0.368 & $<0.001$ & $-0.78(0.72)$ & $-1.45(1.05)$ & $<0.001$ \\
BTP $(\%)$ & -0.526 & $<0.001$ & -0.226 & 0.017 & $3.1(0.4)$ & $2.6(0.3)$ & $<0.001$ \\
\hline
\end{tabular}

Pearson correlations controlling for RA.

$T_{\text {lumbar, }}, \mathrm{BTD}_{\text {lumbar }}$, and $Z_{\mathrm{wb}}$ had no significant correlations/differences.

MPD: menopause duration; sd: standard deviations; ns: not significant; wb: whole body.

TABLE 4: Correlation of wbDXA bone indices and anthropometric indices $(n=141)$.

\begin{tabular}{|c|c|c|c|c|c|c|c|c|}
\hline & & $H$ & $M$ & $\mathrm{AC}$ & $\mathrm{HC}$ & WHR & BMI & CI \\
\hline \multirow{2}{*}{ wbBTD } & $r$ & 0.231 & 0.320 & 0.209 & 0.238 & ns & 0.275 & 0.257 \\
\hline & $P$ & 0.001 & $<0.001$ & 0.014 & 0.005 & ns & 0.001 & 0.002 \\
\hline \multirow{2}{*}{ wbBTM } & $r$ & 0.546 & 0.639 & 0.440 & 0.529 & ns & 0.493 & 0.482 \\
\hline & $P$ & $<0.001$ & $<0.001$ & $<0.001$ & $<0.001$ & $\mathrm{~ns}$ & $<0.001$ & $<0.001$ \\
\hline \multirow{2}{*}{$Z_{\mathrm{wb}}$} & $r$ & 0.192 & 0.266 & ns & 0.181 & ns & 0.232 & 0.215 \\
\hline & $P$ & 0.024 & 0.002 & $\mathrm{~ns}$ & 0.033 & $\mathrm{~ns}$ & 0.006 & 0.011 \\
\hline \multirow{2}{*}{$T_{\mathrm{wb}}$} & $r$ & 0.209 & 0.330 & 0.213 & 0.242 & $\mathrm{~ns}$ & 0.296 & 0.267 \\
\hline & $P$ & 0.011 & $<0.001$ & 0.012 & 0.004 & $\mathrm{~ns}$ & $<0.001$ & 0.001 \\
\hline \multirow{2}{*}{ BTP } & $r$ & ns & -0.660 & -0.713 & -0.718 & -0.325 & -0.683 & -0.671 \\
\hline & $P$ & $\mathrm{~ns}$ & $<0.001$ & $<0.001$ & $<0.001$ & $<0.001$ & $<0.001$ & $<0.001$ \\
\hline \multirow{2}{*}{$\mathrm{BTD}_{\text {lumbar }}$} & $r$ & ns & ns & ns & ns & 0.195 & ns & ns \\
\hline & $P$ & ns & $\mathrm{ns}$ & ns & ns & 0.021 & ns & ns \\
\hline \multirow{2}{*}{$T_{\text {lumbar }}$} & $r$ & ns & ns & ns & ns & 0.195 & ns & $\mathrm{ns}$ \\
\hline & $P$ & ns & $\mathrm{ns}$ & ns & $\mathrm{ns}$ & 0.021 & ns & ns \\
\hline
\end{tabular}

Bivariate partial correlations controlling for age and RA.

Sd: standard deviation, H: height, M: body mass; ns: not significant. 
TABLE 5: wbDXA bone indices according to cardiovascular morbidity $(n=141)$.

\begin{tabular}{|c|c|c|c|c|c|c|}
\hline & Nonobese $(n=92)$ & Obese $(n=49)$ & $P$ & $\operatorname{Nfpg}(n=73)$ & HFPG $(n=68)$ & $P$ \\
\hline wbBTD $\left(\mathrm{g} / \mathrm{cm}^{2}\right)$ & $0.771(0.091)$ & $0.795(0.096)$ & ns & $0.762(0.095)$ & $0.798(0.088)$ & 0.022 \\
\hline wbBTM (kg) & $1.46(0.21)$ & $1.63(0.30)$ & $<0.001$ & $1.46(0.22)$ & $1.57(0.28)$ & 0.012 \\
\hline$Z_{\mathrm{wb}}(\mathrm{sd})$ & $-1.06(0.84)$ & $-0.65(0.99)$ & 0.011 & $-1.16(0.84)$ & $-0.65(0.92)$ & 0.001 \\
\hline$T_{\mathrm{wb}}(\mathrm{sd})$ & $-1.4(0.99)$ & $-1.1(1)$ & ns & $-1.51(1)$ & $-1.10(0.9)$ & 0.017 \\
\hline \multirow[t]{2}{*}{ BTP (\%) } & $2.9(0.3)$ & $2.5(0.3)$ & $<0.011$ & $2.9(0.3)$ & $2.5(0.3)$ & ns \\
\hline & No IS $(n=68)$ & With IS $(n=73)$ & $P$ & No IHD $(n=62)$ & With IHD $(n=79)$ & $P$ \\
\hline BTP (\%) & $2.8(0.4)$ & $2.6(0.4)$ & 0.018 & $2.8(0.4)$ & $2.6(0.2)$ & 0.004 \\
\hline $\operatorname{BTD}_{\text {lumbar }}\left(\mathrm{g} / \mathrm{cm}^{2}\right)$ & $0.907(0.164)$ & $0.838(0.205)$ & 0.030 & $0.878(0.186)$ & $0.858(0.196)$ & ns \\
\hline \multirow[t]{2}{*}{$\mathrm{T}_{\text {lumbar }}(\mathrm{sd})$} & $-0.28(1.2)$ & $-0.79(1.5)$ & 0.030 & $-0.49(1.3)$ & $-0.63(1.4)$ & ns \\
\hline & No MS $(n=55)$ & With MS $(n=86)$ & $P$ & No DM $(n=128)$ & With DM $(n=13)$ & $P$ \\
\hline \multirow[t]{2}{*}{ BTP (\%) } & $2.9(0.4)$ & $2.6(0.3)$ & $<0.001$ & $2.8(0.4)$ & $2.4(0.3)$ & 0.001 \\
\hline & No DL $(n=25)$ & With DL $(n=116)$ & $P$ & No AHT $(n=62)$ & With AHT $(n=79)$ & $P$ \\
\hline BTP (\%) & $2.9(0.4)$ & $2.7(0.3)$ & 0.004 & $2.9(0.4)$ & $2.6(0.3)$ & $<0.001$ \\
\hline
\end{tabular}

Sd: standard deviation; ns: not significant; n/Hfpt: normal/high plasma fasting glucose; IS: inflammatory syndrome; DL: dyslipidemia; MS: metabolic syndrome.

that BMI-defined obesity protects from osteoporosis, most likely by means of adipocyte estrogen production [34, 35]. This protective effect is not warranted though [36]. Our data offer an extra argument in favor of obesity's antiosteoporotic effect: patients with BMI $>30 \mathrm{~kg} / \mathrm{m}^{2}$ have a higher whole body bone mass and a lower bone percent than patients with BMI $<30 \mathrm{~kg} / \mathrm{m}^{2}$. However, if we define obesity by body fat percent, this observation reverses. This apparent contradiction, noted also by Migliaccio et al. [35], resides in the definition of bone percent, defined as bone mass divided by body mass: BMI-defined obese individuals have a slightly higher bone mass than nonobese individuals, but their fat mass is disproportionally higher, enough to produce a smaller bone percent. This explains the difference in BTP, but why do BMI-defined obese individuals have more bone? Our data indicate that BMI-defined obese and nonobese patients have similar height $(159.4 \mathrm{~cm} ; P>0.1)$ and similar bone density. Therefore, BMI-defined obese individuals must have thicker and/or wider bones.

The second comment refers to the unusual behavior with regard to wbDXA bone indices when the study population sample was divided in two subgroups according to glycemia values: hyperglycemic patients behaved exactly like obese patients. It is possible that this effect is the consequence of the significantly higher obesity prevalence among hyperglycemic patients $(50 \% ; 34 / 68)$ than in normal glycemic patients (20.5\%; 15/73; $P<0.001)$.

Lastly, we must mention the effect of inflammation on wbDXA bone indices, namely, that patients with elevated inflammatory markers had less bone in terms of density and body percent. Moreover, inflammation markers correlated significantly with the anthropometric predictors of cardiovascular morbidity and mortality: ESR correlated positively with AC $(r=0.175 ; P=0.038)$ and $\mathrm{HC}(r=0.184$; $P=0.029)$ and negatively with HDL $(r=-0.258 ; P=$ $0.002)$, while CRP correlated positively with body mass $(r=$ $0.215 ; P=0.011)$, AC $(r=0.258 ; P=0.002), \mathrm{HC}$ $(r=0.278 ; P=0.001)$, BMI $(r=0.242 ; P=0.004)$, and CI $(r=0.237 ; P=0.005)$ and negatively with HDL $(r=-0.391 ; P<0.001)$. These observations strengthen the evidence that prove the involvement of inflammation in osteoporosis and atherosclerosis, so well exemplified in RA, but also raises the question of how anthropometry influences the production of inflammatory markers. Integrating these results one must bear in mind study limitations, namely, the cross-sectional design, which did not allow follow-up of these patients, the lack of bone markers measurements, and the use of a surrogate cardiovascular morbidity and mortality marker.

\section{Conclusion}

From a deterministic point of view on atherosclerosis-bone tissue, we noted that on one hand RA patients have significantly lower whole body bone tissue indices and a significantly higher cardiovascular risk compared to normal subject, and that on the other hand inflammation is associated with lower whole body bone tissue indices and is correlated with anthropometric and nonanthropometric cardiovascular risk predictors. These wbDXA bone indices correlate significantly, independently, and negatively with CVR estimation on three different clinical scales. Of all bone measurements, whole body bone percent is the best predictor of CVR, which is the reason for its possible clinical application. The connection between atherosclerosis and osteoporosis is not limited only to the correlation with CVR estimates, but we observed that patients with cardiovascular morbidity (IHD, metabolic syndrome, DM, AHT, and dyslipidemia) had lower wbDXA bone indices. Another established CVR factor, BMIdefined obesity, is associated with a higher whole body bone mass. This bone tissue surplus in obese patients was not accounted by whole body bone density nor by height; therefore it is probably explained by higher individual bone thickness and/or width. 


\section{Conflict of Interests}

The authors declare that there is no conflict of interests regarding the publication of this paper.

\section{References}

[1] D. den Uyl, M. T. Nurmohamed, L. H. D. van Tuyl, H. G. Raterman, and W. F. Lems, "(Sub)clinical cardiovascular disease is associated with increased bone loss and fracture risk, a systematic review of the association between cardiovascular disease and osteoporosis," Arthritis Research and Therapy, vol. 13, no. 1, article R5, 2011.

[2] G. N. Farhat and J. A. Cauley, "The link between osteoporosis and cardiovascular disease," Clinical Cases in Mineral and Bone Metabolism, vol. 5, no. 1, pp. 19-34, 2008.

[3] D. P. Kiel, L. I. Kauppila, L. A. Cupples, M. T. Hannan, C. J. O'Donnell, and P. W. F. Wilson, "Bone loss and the progression of abdominal aortic calcification over 25 year period: the Framingham Heart Study," Calcified Tissue International, vol. 68 , no. 5, pp. 271-276, 2001

[4] G. N. Farhat, A. B. Newman, K. Sutton-Tyrrell et al., "The association of bone mineral density measures with incident cardiovascular disease in older adults," Osteoporosis International, vol. 18, no. 7, pp. 999-1008, 2007.

[5] J. H. Magnus and D. L. Broussard, "Relationship between bone mineral density and myocardial infarction in US adults," Osteoporosis International, vol. 16, no. 12, pp. 2053-2062, 2005.

[6] M. E. Mussolino, J. H. Madans, and R. F. Gillum, "Bone mineral density and mortality in women and men: the NHANES I epidemiologic follow-up study," Annals of Epidemiology, vol. 13, no. 10, pp. 692-697, 2003.

[7] J. S. Chen, C. Hogan, G. Lyubomirsky, and P. N. Sambrook, "Women with cardiovascular disease have increased risk of osteoporotic fracture," Calcified Tissue International, vol. 88, no. 1, pp. 9-15, 2011.

[8] A. Fisher, W. Srikusalanukul, M. Davis et al., "Cardiovascular diseases in older patients with osteoporotic hip fracture: prevalence, disturbances in mineral and bone metabolism, and bidirectional links," Journal of Clinical Interventions in Aging, vol. 8, pp. 239-256, 2013.

[9] H. Maradit-Kremers, P. J. Nicola, C. S. Crowson, K. V. Ballman, and S. E. Gabriel, "Cardiovascular death in rheumatoid arthritis: a population-based study," Arthritis and Rheumatism, vol. 52, no. 3, pp. 722-732, 2005.

[10] J. A. Aviña-Zubieta, H. K. Choi, M. Sadatsafavi, M. Etminan, J. M. Esdaile, and D. Lacaille, "Risk of cardiovascular mortality in patients with rheumatoid arthritis: a meta-analysis of observational studies," Arthritis Care and Research, vol. 59, no. 12, pp. 1690-1697, 2008.

[11] S. Wållberg-Jonsson, H. Johansson, M. L. Öhman, and S. Rantapää-Dahlqvist, "Extent of inflammation predicts cardiovascular disease and overall mortality in seropositive rheumatoid arthritis. A retrospective cohort study from disease onset," Journal of Rheumatology, vol. 26, no. 12, pp. 2562-2571, 1999.

[12] I. del Rincón, D. H. O’Leary, G. L. Freeman, and A. Escalante, "Acceleration of atherosclerosis during the course of rheumatoid arthritis," Atherosclerosis, vol. 195, no. 2, pp. 354-360, 2007.
[13] M. A. Gonzalez-Gay, C. Gonzalez-Juanatey, and J. Martin, "Rheumatoid arthritis: a disease associated with accelerated atherogenesis," Seminars in Arthritis and Rheumatism, vol. 35, no. 1, pp. 8-17, 2005.

[14] N. Rexhepaj, G. Bajraktari, I. Berisha et al., "Left and right ventricular diastolic functions in patients with rheumatoid arthritis without clinically evident cardiovascular disease," International Journal of Clinical Practice, vol. 60, no. 6, pp. 683-688, 2006.

[15] C. P. Chung, J. T. Giles, M. Petri et al., "Prevalence of traditional modifiable cardiovascular risk factors in patients with rheumatoid arthritis: Comparison with control subjects from the multi-ethnic study of atherosclerosis," Seminars in Arthritis and Rheumatism, vol. 41, no. 4, pp. 535-544, 2012.

[16] M. J. Peters, D. P. Symmons, D. McCarey et al., "EULAR evidence-based recommendations for cardiovascular risk management in patients with rheumatoid arthritis and other forms of inflammatory arthritis," Annals of the Rheumatic Diseases, vol. 69, no. 2, pp. 325-331, 2010.

[17] M. J. L. Peters, V. P. van Halm, A. E. Voskuyl et al., "Does rheumatoid arthritis equal diabetes mellitus as an independent risk factor for cardiovascular disease? A prospective study," Arthritis Care and Research, vol. 61, no. 11, pp. 1571-1579, 2009.

[18] G. Haugeberg, T. Uhlig, J. A. Falch et al., "Bone mineral density and frequency of osteoporosis in female patients with rheumatoid arthritis: results from 394 patients in the Oslo County Rheumatoid Arthritis register," Arthritis \& Rheumatology, vol. 43, no. 3, pp. 522-530, 2000.

[19] L. Sinigaglia, A. Nervetti, Q. Mela et al., "A multicenter cross sectional study on bone mineral density in rheumatoid arthritis," Journal of Rheumatology, vol. 27, no. 11, pp. 2582-2589, 2000.

[20] A. Gough, P. Sambrook, J. Devlin et al., "Osteoclastic activation is the principal mechanism leading to secondary osteoporosis in rheumatoid arthritis," Journal of Rheumatology, vol. 25, no. 7, pp. 1282-1289, 1998.

[21] S. Xu, Y. Wang, J. Lu et al., "Osteoprotegerin and RANKL in the pathogenesis of rheumatoid arthritis-induced osteoporosis," Rheumatology International, vol. 32, no. 11, pp. 3397-3403, 2012.

[22] R. E. Ørstavik, G. Haugeberg, T. Uhlig et al., "Incidence of vertebral deformities in 255 female rheumatoid arthritis patients measured by morphometric X-ray absorptiometry," Osteoporosis International, vol. 16, no. 1, pp. 35-42, 2005.

[23] T. M. Huusko, M. Korpela, P. Karppi, V. Avikainen, H. Kautiainen, and R. Sulkava, "Threefold increased risk of hip fractures with rheumatoid arthritis in central Finland," Annals of the Rheumatic Diseases, vol. 60, no. 5, pp. 521-522, 2001.

[24] H. L. Hunter and T. R. Nagy, "Body composition in a seasonal model of obesity: Longitudinal measures and validation of DXA," Obesity Research, vol. 10, no. 11, pp. 1180-1187, 2002.

[25] D. Aletaha, T. Neogi, A. J. Silman et al., "2010 Rheumatoid arthritis classification criteria: an American College of Rheumatology/European League Against Rheumatism collaborative initiative," Arthritis \& Rheumatology, vol. 62, no. 9, pp. 25692581, 2010.

[26] G. Mancia, R. Fagard, K. Narkiewicz et al., "2013 ESH/ESC Guidelines for the management of arterial hypertension," Blood Press, vol. 22, no. 4, pp. 193-278, 2013.

[27] S. D. Fihn, J. M. Gardin, J. Abrams et al., "2012 ACCF/ AHA/ACP/AATS/PCNA/SCAI/STS guideline for the diagnosis and management of patients with stable ischemic heart 
disease: a report of the American College of Cardiology Foundation/American Heart Association task force on practice guidelines, and the American College of Physicians, American Association for Thoracic Surgery, Preventive Cardiovascular Nurses Association, Society for Cardiovascular Angiography and Interventions, and Society of Thoracic Surgeons," Circulation, vol. 126, no. 25, pp. e354-e471, 2012.

[28] P. S. Jellinger, D. A. Smith, A. E. Mehta et al., "American association of clinical endocrinologists' guidelines for management of dyslipidemia and prevention of atherosclerosis," Endocrine Practice, vol. 18, supplement 1, pp. 1-78, 2012.

[29] "Diagnosis and classification of diabetes mellitus," Diabetes Care, vol. 36, supplement 1, pp. S67-S74, 2013.

[30] K. G. M. M. Alberti and P. Zimmet, "Metabolic syndromea new world-wide definition. A consensus statement from the International Diabetes Federation," Diabetic Medicine, vol. 23, no. 5, pp. 469-480, 2006.

[31] J. Perk, G. De Backer, H. Gohlke et al., "European Guidelines on cardiovascular disease prevention in clinical practice (version 2012). The 5th Joint Task Force of the European Society of Cardiology and Other Societies on Cardiovascular Disease Prevention in Clinical Practice (constituted by representatives of nine societies and by invited experts)," European Heart Journal, vol. 33, no. 13, pp. 1635-1701, 2012.

[32] P. Cullen, H. Schulte, and G. Assmann, "The Munster Heart Study (PROCAM): total mortality in middle-aged men is increased at low total and LDL cholesterol concentrations in smokers but not in nonsmokers," Circulation, vol. 96, no. 7, pp. 2128-2136, 1997.

[33] K. Shibuya, H. Hagino, Y. Morio, and R. Teshima, "Crosssectional and longitudinal study of osteoporosis in patients with rheumatoid arthritis," Clinical Rheumatology, vol. 21, no. 2, pp. $150-158,2002$.

[34] C. S. Chang, Y. F. Chang, M. W. Wang et al., "Inverse relationship between central obesity and osteoporosis in osteoporotic drug naive elderly females: the Tianliao Old People (TOP) Study," Journal of Clinical Densitometry, vol. 16, no. 2, pp. 204-211, 2013.

[35] S. Migliaccio, E. A. Greco, R. Fornari et al., "Is obesity in women protective against osteoporosis?” Diabetes, Metabolic Syndrome and Obesity, vol. 4, pp. 273-282, 2011.

[36] E. A. Greco, R. Fornari, F. Rossi et al., "Is obesity protective for osteoporosis? Evaluation of bone mineral density in individuals with high body mass index," International Journal of Clinical Practice, vol. 64, no. 6, pp. 817-820, 2010. 


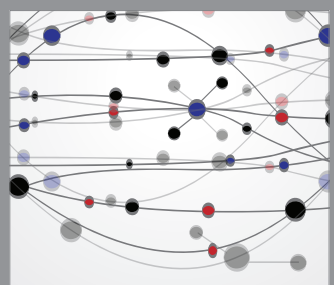

The Scientific World Journal
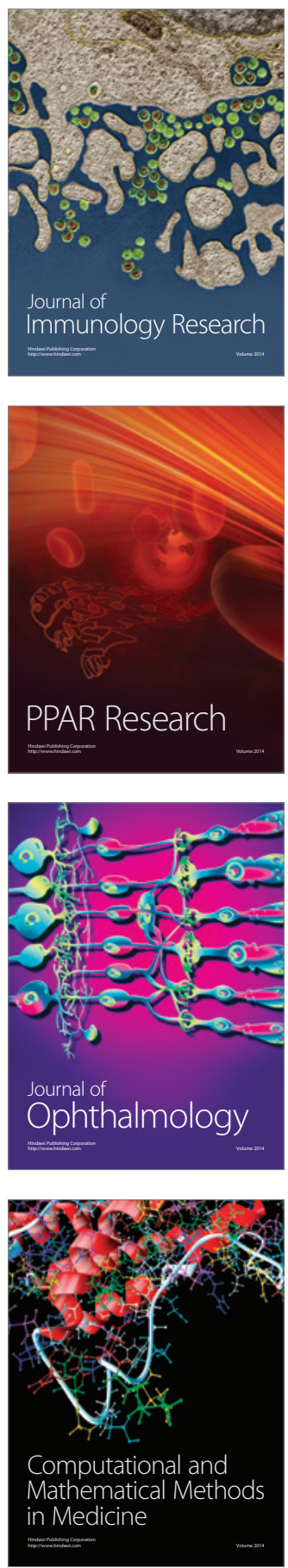

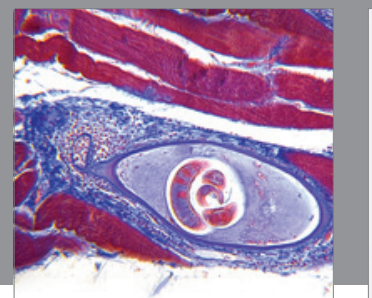

Gastroenterology

Research and Practice
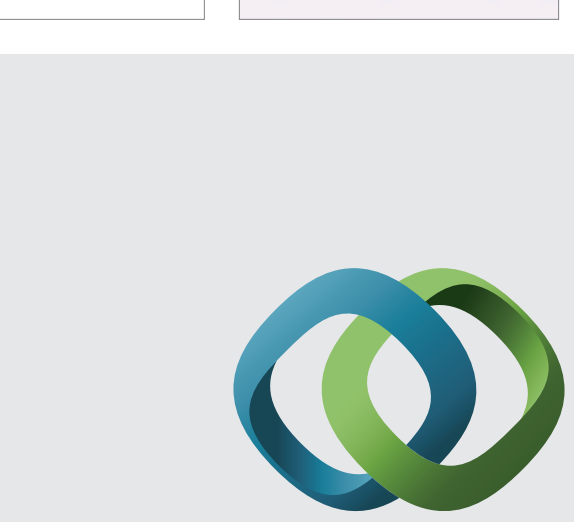

\section{Hindawi}

Submit your manuscripts at

http://www.hindawi.com
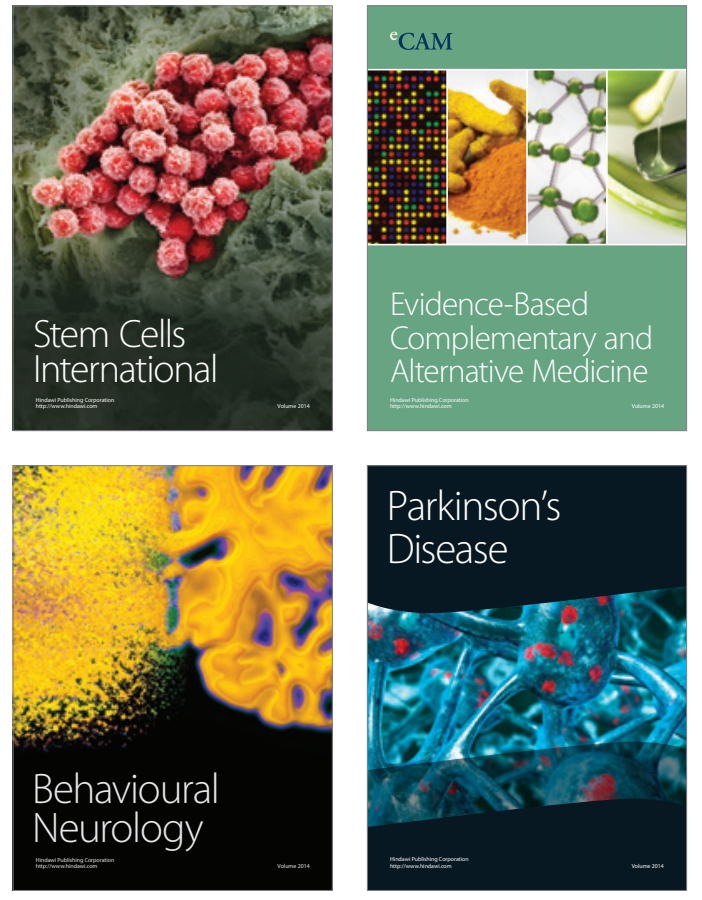
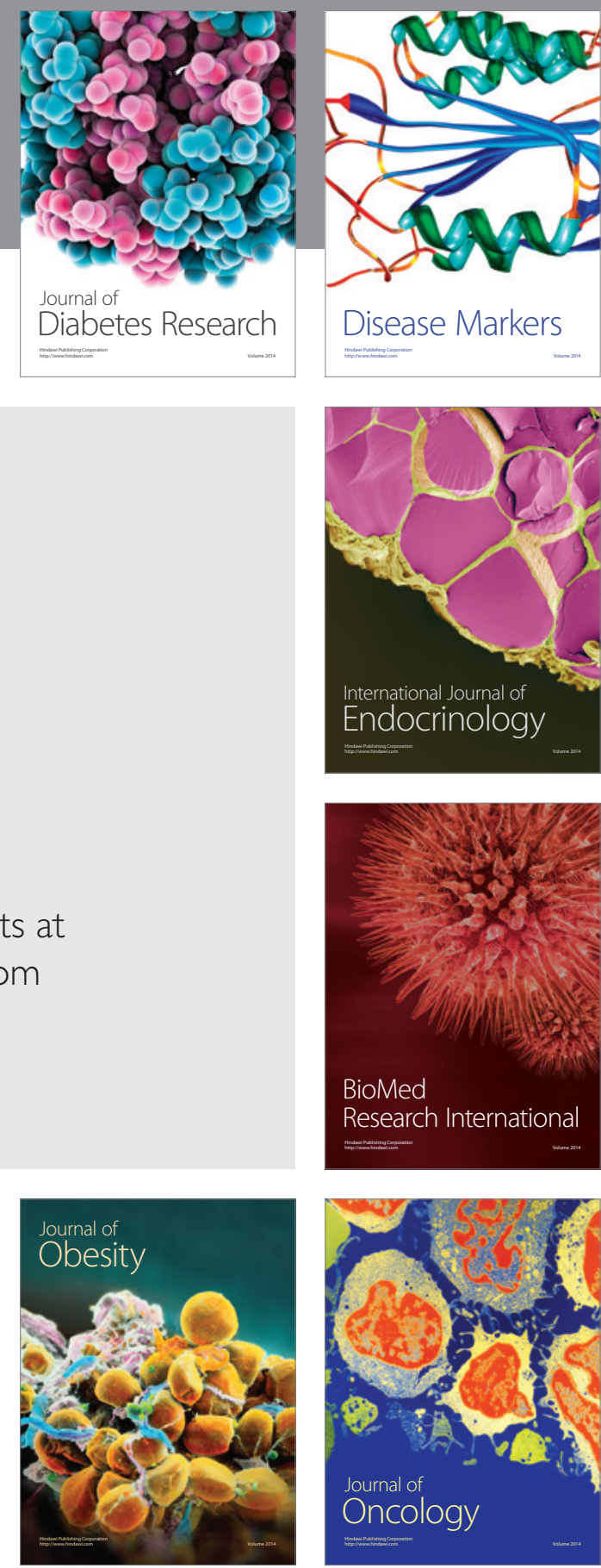

Disease Markers
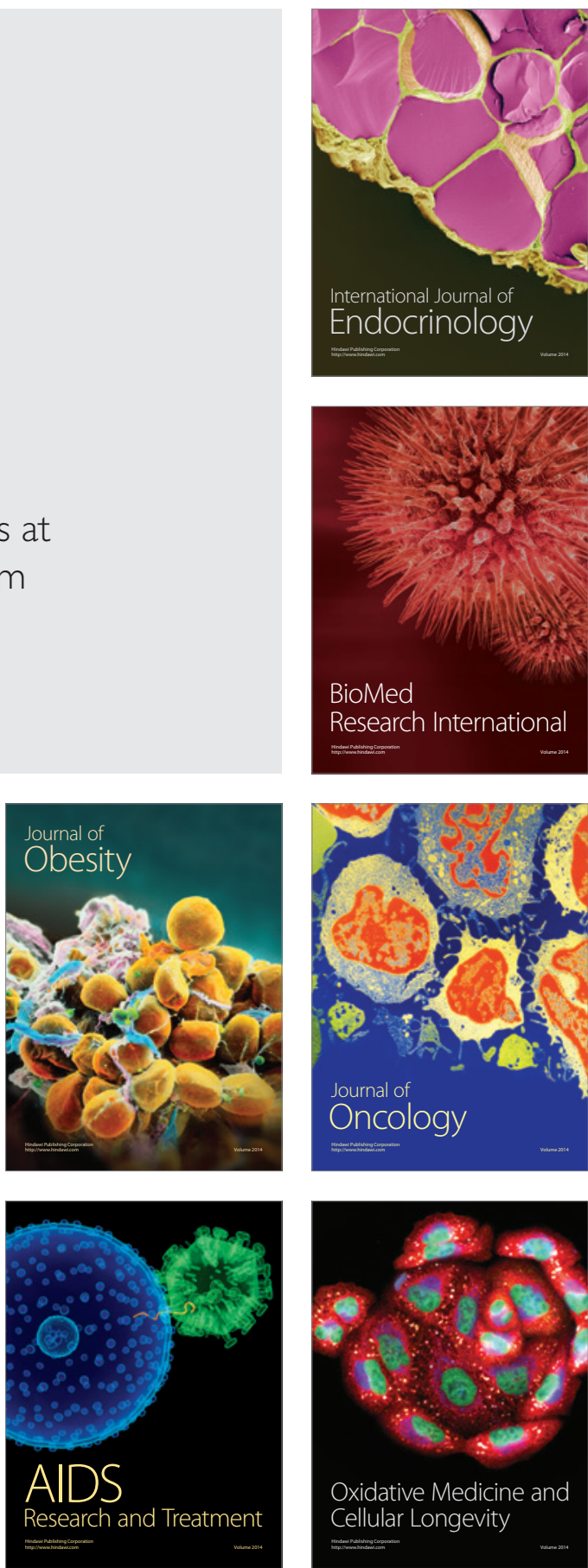